\title{
Implicit and explicit attitudes toward smoking in a smoking and a nonsmoking setting
}

Citation for published version (APA):

Huijding, J. ., de Jong, P. J., Wiers, R. W. H. J., \& Verkooijen, K. (2005). Implicit and explicit attitudes toward smoking in a smoking and a nonsmoking setting. Addictive Behaviors, 30(5), 949-961. https://doi.org/10.1016/j.addbeh.2004.09.014

Document status and date:

Published: 01/01/2005

DOI:

10.1016/j.addbeh.2004.09.014

Document Version:

Publisher's PDF, also known as Version of record

\section{Please check the document version of this publication:}

- A submitted manuscript is the version of the article upon submission and before peer-review. There can be important differences between the submitted version and the official published version of record.

People interested in the research are advised to contact the author for the final version of the publication, or visit the DOI to the publisher's website.

- The final author version and the galley proof are versions of the publication after peer review.

- The final published version features the final layout of the paper including the volume, issue and page numbers.

Link to publication

\footnotetext{
General rights rights.

- You may freely distribute the URL identifying the publication in the public portal. please follow below link for the End User Agreement:

www.umlib.nl/taverne-license

Take down policy

If you believe that this document breaches copyright please contact us at:

repository@maastrichtuniversity.nl

providing details and we will investigate your claim.
}

Copyright and moral rights for the publications made accessible in the public portal are retained by the authors and/or other copyright owners and it is a condition of accessing publications that users recognise and abide by the legal requirements associated with these

- Users may download and print one copy of any publication from the public portal for the purpose of private study or research.

- You may not further distribute the material or use it for any profit-making activity or commercial gain

If the publication is distributed under the terms of Article $25 \mathrm{fa}$ of the Dutch Copyright Act, indicated by the "Taverne" license above, 


\title{
Implicit and explicit attitudes toward smoking in a smoking and a nonsmoking setting
}

\author{
Jorg Huijding ${ }^{\mathrm{a}, *}$, Peter J. de Jong ${ }^{\mathrm{a}}$, Reinout W. Wiers ${ }^{\mathrm{b}}$, Kirsten Verkooijen ${ }^{\mathrm{c}}$ \\ a Department of Clinical and Developmental Psychology, University of Groningen, Grote Kruisstraat 2/1, \\ 9712 TS Groningen, The Netherlands \\ ${ }^{\mathrm{b}}$ Department of Experimental Psychology, Maastricht University, Maastricht, The Netherlands \\ ${ }^{\mathrm{c}}$ University of Southern Denmark, Denmark
}

\begin{abstract}
To test whether global smoking attitudes may be a driving factor in smoking behavior, Experiment 1 assessed smoking associations with the Implicit Association Test (IAT). Although smokers' attitudes $(N=24)$ were less negative than those of nonsmokers $(N=24)$, both displayed negative associations with smoking. To test whether these findings may be an artifact of measurement setting and/or the indirect measure that was used, Experiment 2 assessed attitudes in a smoking $(N=20)$ or a nonsmoking setting $(N=20)$ using the IAT and an Affective Simon Task. In both settings, negative attitudes emerged, suggesting that global (implicit) attitudes may be a moderating rather than a driving factor in smoking behavior. (C) 2004 Elsevier Ltd. All rights reserved.
\end{abstract}

Keywords: Smoking; Implicit attitudes; Implicit association test; Affective Simon Task

\section{Introduction}

Several theorists have argued that people's attitudes may be an important determinant of unhealthy behaviors, like smoking (e.g., Ajzen, 2001). From such a perspective, one would

\footnotetext{
The experiment reported in this paper was conducted at the Department of Medical, Clinical, and Experimental Psychology, Maastricht University, The Netherlands.

* Corresponding author. Tel.: +31 5036368 25; fax: +31 503637602.

E-mail address: J.Huijding@PPSW.rug.n1 (J. Huijding).
} 
expect smokers' attitude toward smoking to be positive (e.g., due to its reinforcing qualities). Following this, positive attitudes towards smoking might be one of the driving forces behind the persistence of smoking behavior. However, studies using self-report measures revealed that smokers' global attitude toward smoking is negative to neutral rather than positive (e.g., Chassin, Presson, Sherman, \& Edwards, 1991; Swanson, Rudman, \& Greenwald, 2001). This suggests that factors other than global attitudes are the motor behind smoking behavior. Meanwhile, due to the stigmatized character of smoking, the validity of explicit attitude measures may be undermined by self-presentational bias. It could be that smokers are in fact characterized by a positive global attitude toward smoking but are unwilling to reveal this. In order to test such a hypothesis, it would be important to complement self-report measures with indirect measures of (automatic) associations. Measures of automatic associations may provide a more accurate reflection of attitudes that are sensitive to self-presentational concerns (e.g., de Jong, 2002; Greenwald \& Banaji, 1995; Greenwald, McGhee, \& Schwarz, 1998).

In a first exploration of implicit attitudes in a US sample of smokers, Swanson et al. (2001) found smokers' implicit attitudes toward smoking to be more positive than that of nonsmokers (Experiment 3), but overall verbal and pictorial smoking stimuli were implicitly more strongly associated with negative than with positive attributes. These findings cast doubt on the idea that habitual smokers' attitudes toward smoking are an important driving force in the continuation of smoking.

However, several characteristics of this study call for an additional exploration of smokers' (implicit) attitudes toward smoking. Obviously, it would be important to see whether the previous findings reflect a robust phenomenon and whether similar attitudes emerge in cultural contexts that are more tolerant towards cigarette smoking than the US. A second issue that merits further research concerns the type of measurement instrument that Swanson et al. (2001) used to assess implicit attitudes toward smoking: the Implicit Association Test (IAT; Greenwald et al., 1998). Inherent to its design, the IAT assesses the strength of associations between a target and attributes relative to a contrast category. Thus, the IAT effects reported by Swanson et al. (2001) may at least partly reflect automatic attitudes toward the contrasts that were used (e.g., sweets, exercise). Similarly, IAT effects obtained using an apparently opposing contrast category (e.g., nonsmoking; Swanson et al., 2001, Experiment 3) do not necessarily reflect attitudes towards smoking per se and may depend on the particular stimuli that were used. In addition, there is evidence that participants may employ specific response strategies that facilitate responding on specific target-attribute combinations regardless of preexisting evaluative associations (see De Houwer, 2002 for a discussion). Thus, the negative attitude toward smoking-related stimulus words that was found by Swanson et al. may be (partly) due to task features of the particular IATs that were used. A third issue that would be important to explore is the influence of context on smokers attitudes. It has been found that the situational context (highlighting a specific aspect of a stimulus) and internal context (e.g., being deprived of nicotine or not) may influence emerging attitudes (Sherman, Presson, Chassin, Rose, \& Koch, 2003). Furthermore, it has been argued that different associations between a context and certain behavioral responses can coexist and that, in such cases, a different context can 
yield a different response (Bouton, 2002). An (learned) association with contextual cues may thus define the relevance of an attitude and thereby the accessibility of that particular attitude (see also Dols, van den Hout, Kindt, \& Willems, 2002 for an application of this rationale on craving). In line with this, it has been shown that participants who were deprived of nicotine and exposed to smoking cues generated more positive characteristics of smoking within a fixed time span than smokers in a noncued condition (e.g., Sayette \& Hufford, 1997). Following this, it might well be that the previously found negative attitude towards smoking may have been due to the actual measurement setting. Inasmuch as it is clearly prohibited to smoke in a lab, smoking-relevant attitudes may not have been triggered and/or rendered inaccessible (see for a similar argument for alcohol Wall, McKee, Hinson, \& Goldstein, 2001).

To explore these important issues, two experiments were designed. As a first step, Experiment 1 aimed to assess whether the findings of Swanson et al. (2001) were replicable in a Dutch student sample. Experiment 2 was designed to explore to what extent the type of measurement instrument and the setting in which attitudes were assessed may have influenced the previous results. One way to circumvent the interpretational problems associated with the contrast category used in the IAT is to use a neutral contrast (cf. De Houwer, 2002; de Jong, Pasman, Kindt, \& van den Hout, 2001; de Jong, van den Hout, Rietbroek, \& Huijding, 2003). Therefore, we adapted the IAT accordingly. Another strategy would be to use a nonrelative measure of automatic associations rather than the IAT. Therefore, we supplemented the IAT with the Affective Simon Task (AST; De Houwer \& Eelen, 1998, for a description, see below). To assess the influence of measurement setting, attitudes were assessed in a neutral lab setting, comparable to the ones used in previous research, and a naturalistic smoking setting. We expected smokers to display positive attitudes toward smoking on both indirect measures and that more positive implicit attitudes would emerge (i.e., are more accessible) in the naturalistic smoking setting than in the nonsmoking lab setting.

\section{Experiment 1}

\subsection{Method}

\subsubsection{Participants}

Twenty-four smoking (15 female) and 24 nonsmoking (17 female) students from Maastricht University (mean age $=21.2$, S.D. $=2.0$ ) participated in return for a chocolate bar. One participant's data were discarded because of his ex-smoking status.

\subsection{Materials}

\subsubsection{Implicit association test}

The IAT is a computerized reaction time task that measures to what extent two target categories are associated with two attribute categories. Participants were instructed to sort 
stimulus words as fast as possible to the appropriate superordinate category using the $\mathrm{P}$ or the $\mathrm{Q}$ on a keyboard. The target categories were smoking and exercise, and the attribute categories were pleasant and unpleasant. Each category consisted of 10 exemplar stimuli (see Appendix A). The IAT consisted of five phases: (1) practice sorting target stimuli to the target categories (smoking vs. exercise); (2) practice sorting attribute stimuli to the attribute categories (pleasant vs. unpleasant); (3) critical combined sorting of all stimuli to both the target and the attribute categories; (4) practice sorting target stimuli with reverse response requirements; (5) critical combined sorting with reversed response requirements for the target. In general, responses tend to be faster when the two categories that share a response key in the combined phases are somehow associated than when they are not. The difference in reaction times (RTs) between phase 3 and 5 reflects whether smoking is associated more strongly with pleasant or unpleasant, relative to the extent to which exercise is associated with either attribute category.

After an incorrect response, the word 'fault' appeared on the screen until the correct answer was given. A 3000-ms response window was used, after which an error was registered. A 250-ms stimulus interval was used. All 10 exemplar stimuli of each category were presented four times in each block. The target-attribute combinations that shared response keys were counterbalanced (i.e., block order) as well as the sequence of target and attribute stimuli presentation.

\subsubsection{Semantic differential}

Participants completed a set of eight semantic differential items for each target concept (smoking and exercise) as an explicit attitude measure. Each item consisted of a polaropposite adjective pair divided on a seven-point scale (see also Swanson et al., 2001). The pairs were good-bad, healthy-unhealthy, sexy-unsexy, pleasant-unpleasant, harmlessharmful, sociable-unsociable, ugly-glamorous, and calming-stressful.

\subsection{Procedure}

Participants were tested individually. They started with the semantic differentials and then completed the IAT.

\section{Results}

\subsection{Implicit association test}

For the two critical phases, mean reaction times (RTs) are shown in Fig. 1. A 2 Concept (smoking, exercise) $\times 2$ Smoking status (smoker, nonsmoker) ANOVA showed a main effect for Concept, $F(1,30)=125.9, p<.01$, indicating that, relative to exercise, participants associated smoking overall stronger with negative attributes than with positive attributes. Meanwhile, as can be seen in Fig. 1, a significant interaction between Smoking status and Concept, $F(1,30)=11.4, p<.01$, showed that this negative association with smoking was significantly weaker for smokers than for nonsmokers. To get an idea of the strength of 


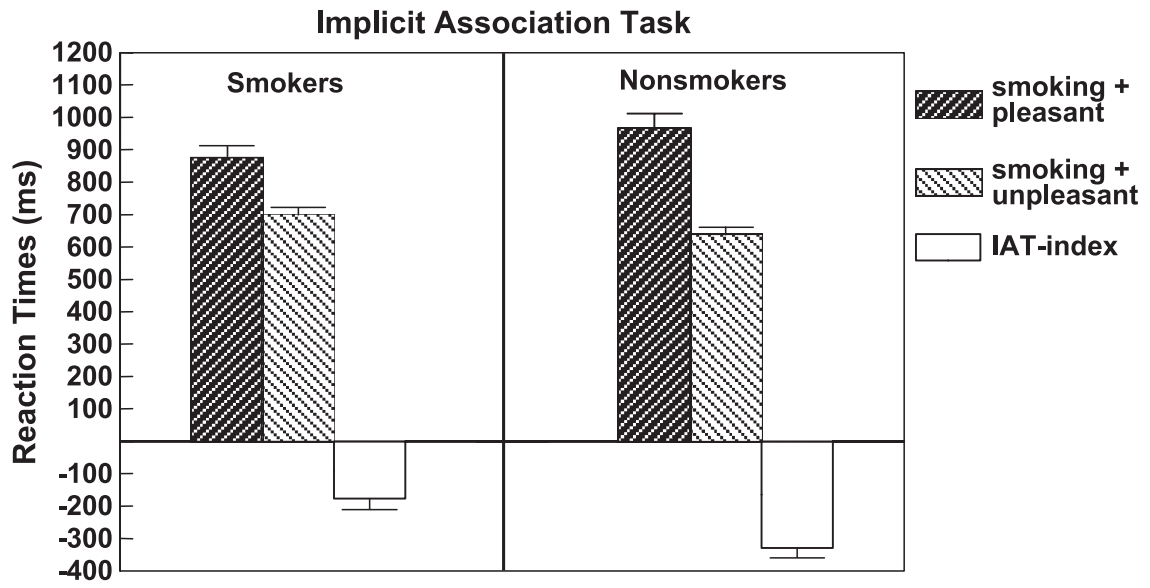

Fig. 1. Mean reaction times in milliseconds for the two critical phases of the IAT and the IAT effect as a function of smoking status in Experiment 1. The bars represent the phase in which smoking shared the response key with "pleasant," the phase in which smoking shared the response key with "unpleasant," and the IAT index as a function for smokers and nonsmokers. The IAT index is the difference score (in reaction times) between the smoking+pleasant and the smoking+unpleasant response assignments. A positive IAT index reflects a relatively strong association between smoking and a positive valence, a negative IAT index reflects a relatively strong association between smoking and a negative valence.

participants' preference for smoking relative to exercise, we calculated an IAT index (cf. de Jong et al., 2003, see Fig. 1). Mean RTs on trials during which the smoke cues shared the response key with positive attributes were subtracted from mean RTs on trials during which the smoke cues shared the response key with negative attributes. In line with Swanson et al.

Table 1

Summary of mean scores (S.D. between parentheses) on the self-report measures for Experiments 1 and 2

\begin{tabular}{|c|c|c|}
\hline \multirow[t]{2}{*}{ Experiment 1 measures } & \multicolumn{2}{|l|}{ Smoking status } \\
\hline & Smoking $(N=24)$ & Nonsmoking $(N=24)$ \\
\hline \multicolumn{3}{|l|}{ Semantic differentials } \\
\hline Smoking & $3.7(0.5)$ & $2.3(0.9)$ \\
\hline Exercise & $5.6(0.6)$ & $6.0(0.5)$ \\
\hline \multirow[t]{2}{*}{ Experiment 2 measures } & \multicolumn{2}{|l|}{ Context } \\
\hline & Smoking $(N=20)$ & Nonsmoking $(N=20)$ \\
\hline \multicolumn{3}{|l|}{ Semantic differentials } \\
\hline Smoking & $3.5(0.35)$ & $3.6(0.69)$ \\
\hline Writing & $5.0(0.91)$ & $4.7(0.63)$ \\
\hline FTQ & $3.4(1.3)$ & $3.9(1.8)$ \\
\hline
\end{tabular}

Note. Semantic differential scores of 4 (range 1-7) represent neutral attitudes. Scores lower than 4 indicate less favorable and scores higher than 4 indicate more favorable attitudes. FTQ=Fagerström Tolerance Questionnaire. 
(2001), the IAT index revealed negative smoking attitudes for both smokers $(M=-176.5$, S.D. $=163.3)$ and nonsmokers $(M=-328.9$, S.D. $=148.4)$, but it showed smokers to be significantly less negative, $t(46)=-3.4, p<.01$.

\subsection{Semantic differential}

Replicating previous research and in line with the implicit measure, the mean score on the smoking differential was more negative than neutral (a score of 4) for smokers, $t(23)=3.3$, $p<.01$, and nonsmokers, $t(23)=9.5, p<.01$ (see Table 1). Meanwhile, smokers rated smoking as significantly less negative than nonsmokers, $t(46)=6.5, p<.01$. Exercise was rated as more positive than neutral by both smokers, $t(23)=-12.4, p<.01$, and nonsmokers, $t(23)=-19.2$, $p<.01$. Yet, nonsmokers rated exercise as significantly more positive than smokers, $t(46)=-2.7, p<.01$.

\section{Experiment 2}

\subsection{Method}

\subsubsection{Participants}

Smoking students (24 females and 24 males) of Maastricht University with a mean age of 25.3 (S.D. =7.5) years participated in return for a chocolate bar. Participants were instructed not to smoke $2 \mathrm{~h}$ prior to the experiment to ensure the desire to smoke was not too low or too high, preventing floor or ceiling effects (e.g., Dols et al., 2002), compliance was checked verbally prior to the experiment.

\subsection{Materials}

\subsubsection{Implicit Association Test}

The IAT used in this experiment was structurally similar to the one used in Experiment 1. However, inasmuch as exercise was rated as positive rather than neutral in Experiment 1, the contrast category exercise was replaced with a more neutral category, writing. Writing comprised of words that had previously been rated as neutral or close to neutral in a normative study (Hermans \& De Houwer, 1994). In addition, only four stimulus words were used per category (see Appendix A), aiming to decrease the demand on participants' attention and concentration. Note that previous research showed that the IAT effects are independent of the number of stimuli used (Greenwald et al., 1998).

\subsubsection{Affective Simon Task}

The AST is a reaction time paradigm designed to capture the unintentional influence of the affective value of a stimulus on task performance. During critical phases of the experiment, participants were instructed to respond as fast as possible with saying 
either Positive! or Negative! to stimulus words, depending on whether they were presented in singular or plural format. Responses are typically faster when the valence of the response is congruent with the valence of the stimulus, although stimulus valence is irrelevant for formulating the correct response (De Houwer, 1997; de Jong et al., 2003), thereby revealing the valence of the word. Four types of words were used: smoking words, writing words, positive words, and negative words (see Appendix A). The AST used here consisted of three phases in which the response times were recorded using a microphone. The AST started with a prime phase (cf. de Jong et al., 2003) aimed at strengthening the bond between the response and the subjective valence of the stimulus word, thus bolstering the affective Simon effect. Participants had to respond to positive words by saying Positive! and to negative words by saying Negative!. Ten universal positive and 10 universal negative nouns (derived from Hermans \& De Houwer, 1994) were presented four times, twice in singular and twice in plural form. None of the words in the priming phase was used in subsequent phases of the task. During phases 2 and 3, participants were instructed to respond with Positive! or Negative! on the basis of word format (singular of plural). Phase 2 consisted of eight smoking and eight writing words. Phase 3 consisted of eight positive and eight negative words (derived from Hermans \& De Houwer, 1994). This phase was included to test whether a general Affective Simon Effect would emerge and functioned as a validation of the present experimental setup (layout, instruction, etc.).

In phases 2 and 3, all stimulus words were presented twice in a singular condition and twice in a plural format. Response requirements were counterbalanced. Participants were instructed to respond as fast and accurately as possible. During phases 2 and 3, the experimenter recorded errors and voice key failures. Stimuli disappeared immediately after the voice key had registered a response. A 3-s response window was used, after which an error response was registered.

\subsubsection{Self-reported attitudes}

Similar to Experiment 1, participants completed a semantic differential to assess explicit attitudes toward smoking.

\subsubsection{Fagerström tolerance questionnaire}

The short version of the FTQ for adolescents was used to estimate participants' selfreported level of nicotine dependence (Prokhorov et al., 2000). This modified FTQ is a sevenitem multiple-choice questionnaire. We used this version because it has better psychometric properties than the adult version.

\subsection{Procedure}

Participants were randomly assigned to the smoking or the nonsmoking setting and were tested individually. The nonsmoking lab setting comprised of a typical soundattenuated laboratory room with only a table with the computer. The smoking setting 
was fit up so that it was clear people smoked there and radiated an informal atmosphere. During the experimental instructions, participants in the smoking setting were told that it was allowed to smoke a cigarette after completing the tests. Meanwhile, the experimenter lit up a cigarette to underline that, in the experiment room, one was indeed allowed to smoke. In the nonsmoking setting, participants were told during the instructions that smoking was prohibited. Participants in both conditions were then asked to complete the self-report measures. In both conditions, half of the participants proceeded with the IAT, while the other half started with the AST. Finally, participants completed the FTQ.

\section{Results}

\subsection{Indirect measures}

\subsubsection{Implicit association test}

Mean RTs for the two critical phases and the IAT index (cf. Experiment 1) are shown in Fig. 2. The pattern of IAT indices did not significantly deviate from a normal distribution. A one-way ANOVA indicated that the IAT indices were significantly smaller than zero, $F(1,38)=24.3, p<.01$. There was no effect of Setting, $F(1,38)<1$, indicating that the negative implicit attitude towards smoking was similar for both the smoking (IAT index $=-136.7$, S.D.=184.8) and the nonsmoking setting (IAT index $=-136.4$, S.D.=164.9). The size of the IAT indices was similar to those of smokers in Experiment 1.

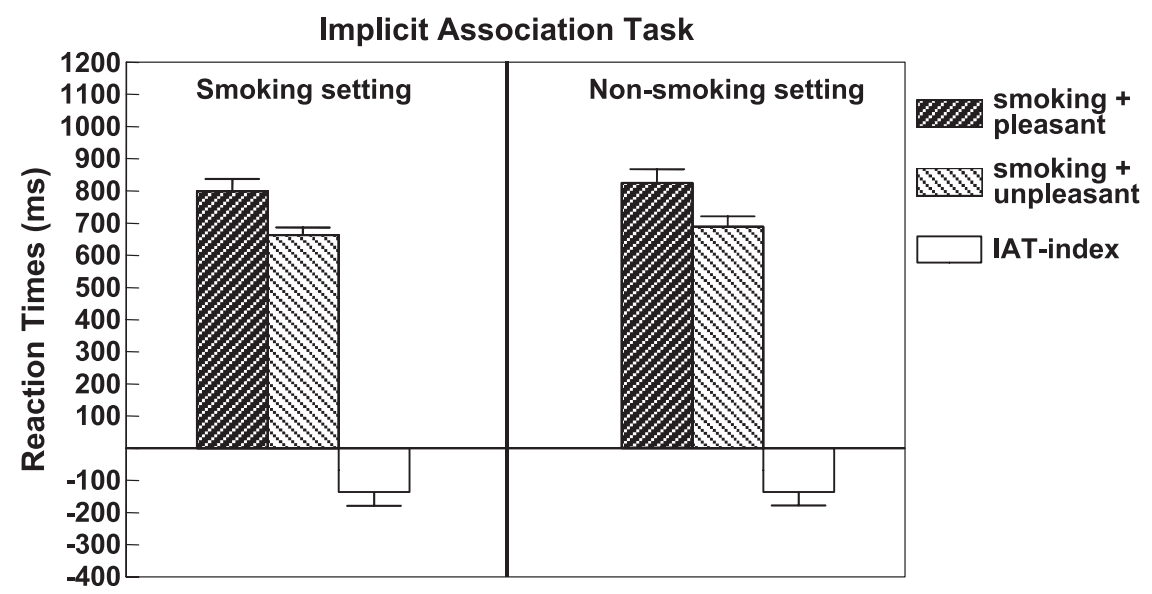

Fig. 2. Mean reaction times in milliseconds for the two critical phases of the IAT and the IAT-index as a function of measurement setting in Experiment 2. A positive IAT index reflects a relatively strong association between smoking and a positive valence, a negative IAT-index reflects a relatively strong association between smoking and a negative valence. 


\subsubsection{Affective Simon Task}

Before the analysis, the data was log-transformed to meet normality criteria. Mean untransformed RTs for positive and negative responses to smoking and writing stimuli are shown in Fig. 3.

\subsubsection{General Affective Simon Effect}

Replicating previous research and sustaining the validity of the present paradigm, participants were generally faster when there was a match between word valence and required response $(M=730 \mathrm{~ms}, \mathrm{~S} . \mathrm{D} .=114)$ than when there was a mismatch $(M=749 \mathrm{~ms}, \mathrm{~S} . \mathrm{D} .=128)$, $t(39)=2.0, p<.05$.

\subsubsection{Smoking Simon Effect}

A Required Response (positive, negative) $\times 2$ Setting (smoking, nonsmoking) ANOVA did not reveal a main effect of Response, $F(1,38)<1$. This indicates that, participants were equally fast responding with Positive or with Negative to smoking stimuli (i.e., neutral implicit attitude toward smoking). This response pattern was independent of measurement setting, $F(1,38)<1$.

\subsubsection{Writing simon effect}

A Required Response (positive, negative) x 2 Setting (smoking, nonsmoking) ANOVA did not reveal a main effect of Response, $F(1,38)<1$, indicating that participants were equally fast responding with Positive or with Negative to writing stimuli (i.e., a neutral attitude). As expected, the response pattern did not differentiate between measurement settings, $F(1,38)<1$.

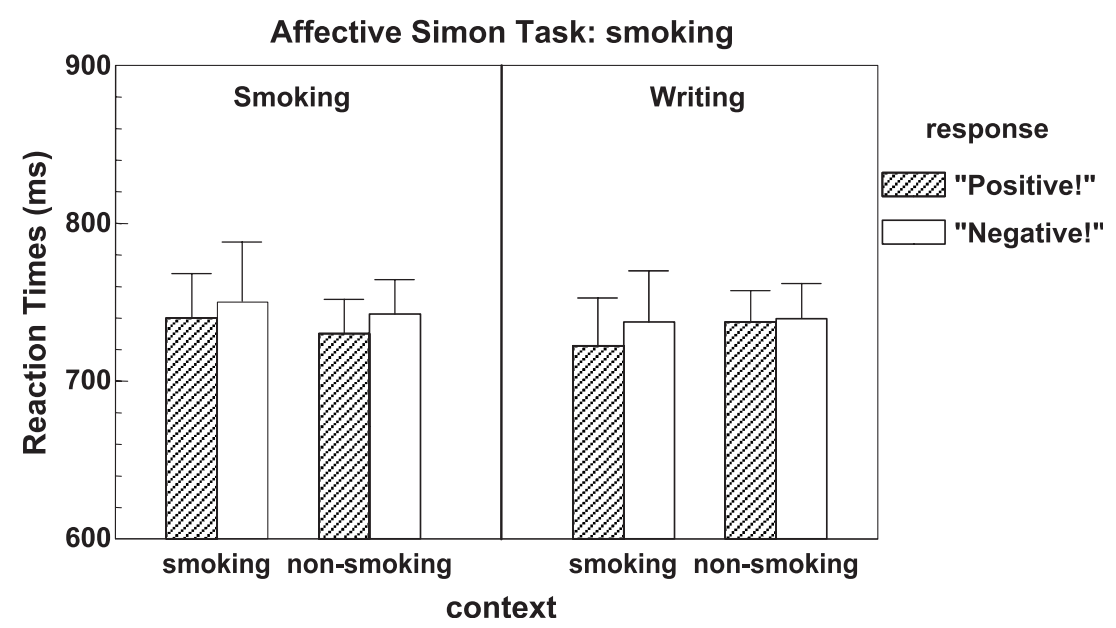

Fig. 3. Mean reaction times in milliseconds for positive and negative responses to smoking or writing related words during the "smoking AST" as a function of context. 


\subsection{Semantic differentials}

Summary statistics of the explicit measures are shown in Table 1. A 2 Setting (smoking, nonsmoking) $\times 2$ Target (smoking, writing) ANOVA of the mean score of the semantic differentials revealed a main effect of Target, $F(1,38)=59.7, p<.001$, but no significant Setting $\times$ Target effect, $F(1,38)=0.2, p>.6$. This indicates that participants rated smoking and writing differently regardless of measurement setting. Subsequent $t$ tests revealed that participants associated smoking overall stronger with negative attributes than with neutral (a score of 4$), t(39)=-4.7, p<.001$, whereas writing was associated overall more strongly with positive attributes than with neutral, $t(39)=6.8, p<.001$.

\subsubsection{Fagerström tolerance questionnaire}

Mean FTQ scores were 3.4 (range=1.0-6.0, S.D.=1.3) and 3.9 (range=2.0-9.0, S.D.=1.8) for participants in the smoking setting and lab setting, respectively. There was no significant difference between both measurement settings in this respect, $t(38)=1.0, p>.2$.

\section{Discussion}

The major results of the present experiments can be summarized as follows: (1) At the explicit level, smokers displayed a negative attitude toward smoking (although less negative than nonsmokers); (2) The IAT differentiated between smokers and nonsmokers; (3) However, the IAT indicates that smokers' global implicit attitude toward smoking is negative rather than positive; (4) The AST revealed a neutral implicit attitude toward smoking cues; (5) Both implicit and explicit attitudes toward smoking were found to be independent of measurement setting.

The results of the self-report measures of Experiments 1 and 2 are in line with previous research (Chassin et al., 1991; Stacy, Bentler, \& Flay, 1994; Swanson et al., 2001) and converge to the conclusion that smokers display negative attitudes toward smoking when explicitly assessed. With respect to habitual smokers' implicit attitudes, none of the indirect measures used in either Experiments 1 or 2 revealed a positive attitude toward smoking. In accordance with Swanson et al. (2001) (Experiment 3), Experiment 1 showed that smokers endorse significantly less negative implicit attitudes toward smoking than nonsmokers. However, the implicit attitudes of both smokers and nonsmokers were negative. Inasmuch as these results may have been due to positive associations with the particular contrast category that was used (i.e., exercise), Experiment 2 aimed to use a more neutral contrast category in the IAT. Nevertheless, in Experiment 2 , the IAT still revealed negative rather than positive implicit attitudes toward smoking cues. This suggests that these findings reflect a robust phenomenon. Meanwhile, it should be acknowledged that, although we only selected stimulus words that were previously rated as being neutral, the contrast category 'writing' was rated as slightly positive on the semantic differential. Therefore, it cannot be ruled out that the level of negativity of participants' implicit attitude toward smoking is (somewhat) inflated due to the positive 
attitude towards writing in the present sample. Nevertheless, the available evidence renders it very unlikely that the failure to find a clear-cut positive implicit attitude towards smoking is due to the contrast concept that was used in the present IAT.

The finding that on the AST participants were equally fast responding with Positive and Negative to smoke-related words suggests a neutral or ambivalent implicit attitude toward smoking cues. The fact that the expected differential response pattern with respect to the general positive and negative words emerged validates the present setup and design and refutes the idea that the neutral response pattern to the smoking stimuli was caused by a lack of sensitivity of the AST.

One of the important aims of the present experiment was to assess the influence of measurement setting on individuals' attitudes. In line with previous research in the context of smoking (Sherman et al., 2003), it was found that the IAT was not influenced by contextual factors. That is, although we expected that typically, in a smoking setting, positive rather than negative attitudes toward smoking would emerge, smokers displayed a negative attitude toward smoking in both measurement settings on both the IAT and the AST. One explanation for this finding may be that changes in context may not interfere with the conscious strategies that participants may use to complete the IAT (cf. Sherman et al., 2003). However, such an explanation is not very convincing as neither, for the AST, an effect of measurement setting emerged. Thus, altogether, the present results seem to indicate that the irrelevance of a nonsmoking lab setting for smoking did not play a crucial role in the absence (i.e., inaccessibility) of positive implicit attitudes toward smoking in previous studies.

It should be acknowledged that effects of a specific setting may only emerge when it elicits strong urge to smoke (cf. Sherman et al., 2003). However, if positive attitudes only emerge after a very strong context manipulation, they can hardly be classified as global attitudes. Thus, the present results suggest that factors other than global attitudes are the primary motor driving smoking behavior. For instance, instead of global attitudes, more specific positive associations with smoking may be crucial, such as associations with particular sensory aspects of smoking (Sherman et al., 2003) or with the arousing properties of smoking (cf. Wiers, van Woerden, Smulders, \& de Jong, 2002). One explanation for the consistent finding that smokers' (implicit and explicit) global attitudes toward smoking are negative may be that they reflect negative associations with smoking, such as unpleasant feelings arising from an uncontrollable urge to smoke or the prospect of a protracted death from lung cancer or coronary heart disease. Similar explanations have been put forward in the context of eating disorders to explain the negative (implicit) attitudes toward high-calorie food that were found in obese individuals (Roefs \& Janssen, 2002) and in the context of negative explicit alcohol expectancies (Jones \& McMahon, 1998).

Although the present results suggests that global attitudes are not a factor driving smoking behavior, it might well be that global attitudes do influence smoking in a more indirect way. In line with previous studies (Swanson et al., 2001; Sherman et al., 2003), smokers' attitudes towards smoking were found to be significantly less negative than nonsmokers' attitudes toward smoking. Accordingly, differences in global (implicit) 
attitudes toward smoking might be important for smoking behavior as a moderating factor. That is, smokers' relatively positive attitudes toward smoking may provide less inhibiting force against other factors that promote smoking behavior.

\section{Acknowledgement}

The authors wish to thank Bert Hoekzema for his technical assistance.

\section{Appendix A. Stimulus words for the Implicit Association Test in Experiments 1 and 2 and the Affective Simon Task}

\begin{tabular}{|c|c|c|}
\hline \multirow[t]{5}{*}{ IAT } & Pleasant: & $\begin{array}{l}\text { Kindness*, peace*, talent*, success*, joy, sunshine, } \\
\text { good, party, warmth, love }\end{array}$ \\
\hline & Unpleasant: & $\begin{array}{l}\text { Assault*, war*, junk*, failure*, abuse, brutal, filth, } \\
\text { bad, slime, vomit }\end{array}$ \\
\hline & Smoking: & $\begin{array}{l}\text { Tobacco*, smoking*, nicotine*, cigarette*, cigar, } \\
\text { smokers, Marlboro, rolling tobacco, ashtray, lighter }\end{array}$ \\
\hline & Exercise: & $\begin{array}{l}\text { Swimming, diving, sports, aerobics training, running } \\
\text { biking, tennis, athletics, exercise }\end{array}$ \\
\hline & Writing*: & Page, ink, letter, writing \\
\hline \multirow[t]{2}{*}{ AST Phase 1} & Positive: & $\begin{array}{l}\text { Embrace, congratulation, party, friend, joke, gift, } \\
\text { friendship, lover, kiss, beauty }\end{array}$ \\
\hline & Negative & $\begin{array}{l}\text { Murder, mutilation, strangulation, carrion, } \\
\text { slaughter, rape, fracture, execution, threat, disaster }\end{array}$ \\
\hline \multirow[t]{2}{*}{ AST Phase 2} & Smoking: & $\begin{array}{l}\text { Cigarette, ashtray, butt, filter cigarette, cigar, } \\
\text { lighter, smoker, smoke room }\end{array}$ \\
\hline & Writing: & $\begin{array}{l}\text { Magazine, newspaper, ballpoint, letter, author, text, } \\
\text { page, paper }\end{array}$ \\
\hline \multirow[t]{2}{*}{ AST Phase 3} & Positive: & $\begin{array}{l}\text { Friend, vacation, summer, flower, present, wish, } \\
\text { rainbow, butterfly }\end{array}$ \\
\hline & Negative: & $\begin{array}{l}\text { Infection, sadist, corpse, disease, war, funeral, exam, } \\
\text { virus }\end{array}$ \\
\hline
\end{tabular}

Note: * indicates words that are used in the IAT of Experiment 2.

\section{References}

Ajzen, I. (2001). Nature and operation of attitudes. Annual Review of Psychology, 52, 27-58.

Bouton, M. E. (2002). Context, ambiguity, and unlearning: sources of relapse after behavioral extinction. Biological Psychiatry, 52, 976-986.

Chassin, L., Presson, C. C., Sherman, S. J., \& Edwards, D. A. (1991). Four pathways to young-adult smoking status: Adolescent social-psychological antecedents in a Midwestern community sample. Health Psychology, $10,409-418$. 
De Houwer, J. (1997). Automatic affect and cognition. Doctoral dissertation. University of Leuven, Belgium.

De Houwer, J. (2002). The Implicit Association Test as a tool for studying dysfunctional associations in psychopathology: Strengths and limitations. Behavior Therapy and Experimental Psychiatry, 33, 115-133.

De Houwer, J., \& Eelen, P. (1998). An affective variant of the Simon Paradigm. Cognition and Emotion, $12,45-61$.

de Jong, P. J. (2002). Implicit self-esteem and social anxiety: Differential self-favouring effects in high and low anxious individuals. Behaviour Research and Therapy, 40, 501-508.

de Jong, P. J., Pasman, W., Kindt, M., \& van den Hout, M. A. (2001). A reaction time paradigm to assess (implicit) complaint-specific dysfunctional beliefs. Behaviour Research and Therapy, 39, 101-113.

de Jong, P. J., van den Hout, M. A., Rietbroek, H., \& Huijding, J. (2003). Dissociations between implicit and explicit attitudes towards phobic stimuli. Cognition and Emotion, 17, 521-545.

Dols, M., van den Hout, M., Kindt, M., \& Willems, B. (2002). The urge to smoke depends on the expectation of smoking. Addiction, 97, 87-93.

Greenwald, A. G., \& Banaji, M. R. (1995). Implicit social cognition: attitudes, self-esteem, and stereotypes. Psychological Review, 102, 4-27.

Greenwald, A. G., McGhee, D. E., \& Schwartz, J. L. K. (1998). Measuring individual differences in implicit cognition. The Implicit Association Test. Journal of Personality and Social Psychology, 74, 1464-1480.

Hermans, D., \& De Houwer, J. (1994). Affective and subjective familiarity ratings of 740 Dutch words. Psychologica Belgica, 34, 115-139.

Jones, B. T., \& McMahon, J. (1998). Alcohol motivations as outcome expectancies. In W. R. Miller, \& N. Heather (Eds.), Treating addictive behaviors, (2nd ed.). Applied Clinical Psychology (pp. 75-91). New York: Plenum Press.

Prokhorov, A. V., De Moor, C., Pallonen, U. E., Hudmon, K. S., Koehly, L., \& Hu, S. (2000). Validation of the Fagerstroem Tolerance Questionnaire with salivary cotinine among adolescents. Addictive Behaviors, 25, 429-433.

Roefs, A., \& Janssen, A. (2002). Implicit and explicit attitudes toward high-fat foods in obesity. Journal of Abnormal Psychology, 111, 517-521.

Sayette, M. A., \& Hufford, M. R. (1997). Effects of smoking urge on generation of smoking related information. Journal of Applied Social Psychology, 27, 1395-1405.

Sherman, S. J., Presson, C. C., Chassin, L., Rose, J. S., \& Koch, K. (2003). Implicit and explicit attitudes toward cigarette smoking: The effects of context and motivation. Journal of Social and Clinical Psychology, 22, 13-39.

Stacy, A. W., Bentler, P. M., \& Flay, B. R. (1994). Attitudes and health behavior in diverse populations: drunk driving, alcohol use, binge eating, marijuana use, and cigarette use. Health Psychology, 13, 73-85.

Swanson, J. E., Rudman, L. A., \& Greenwald, A. G. (2001). Using the Implicit Association Test to investigate attitude-behaviour consistency for stigmatized behaviour. Cognition and Emotion, 15, 207-230.

Wall, A., McKee, S. A., Hinson, R. E., \& Goldstein, A. (2001). Examining alcohol outcome expectancies in laboratory and naturalistic bar settings: A within-subject experimental analysis. Psychology of Addictive Behaviors, 15, 219-226.

Wiers, R. W., van Woerden, N., Smulders, F. T. Y., \& de Jong, P. J. (2002). Implicit and explicit alcohol-related cognitions in heavy and light drinkers. Journal of Abnormal Psychology, 111, 648-658. 